JOHN HOPEWELL $E T$ AL.: RENAL TRANSPLANTATION

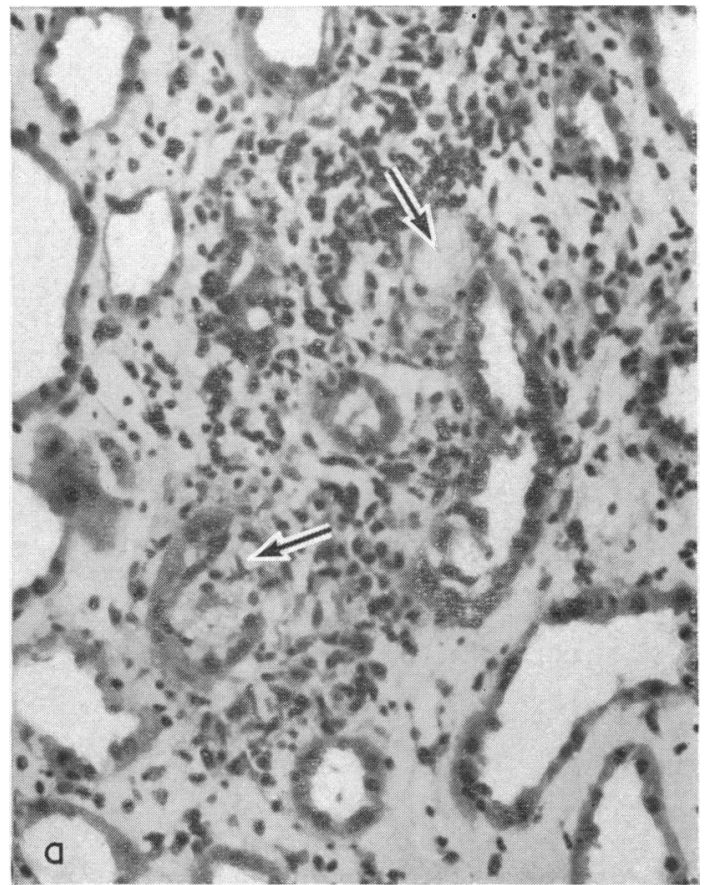

FIg. 1.-Case 3. Renal biopsy on 17 November 1960. (a) Tubules showing cellular infiltration and $x$ 195). (b) Glomerulus and tubules $(\times 220)$.

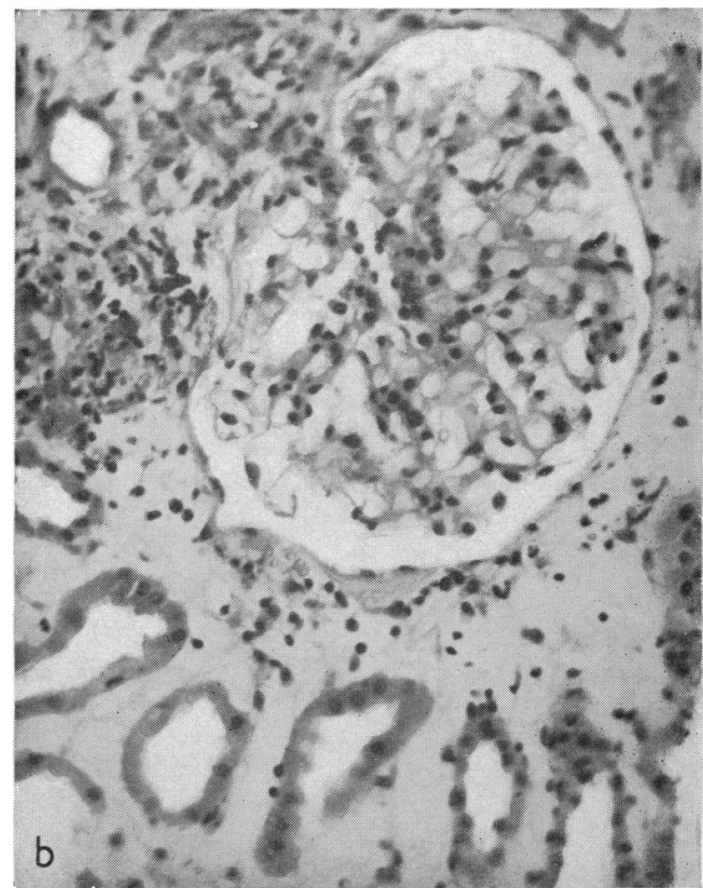

Fig. 2-Case 3, Renal transplant post mortem. Glomerulus
between two red infarcts
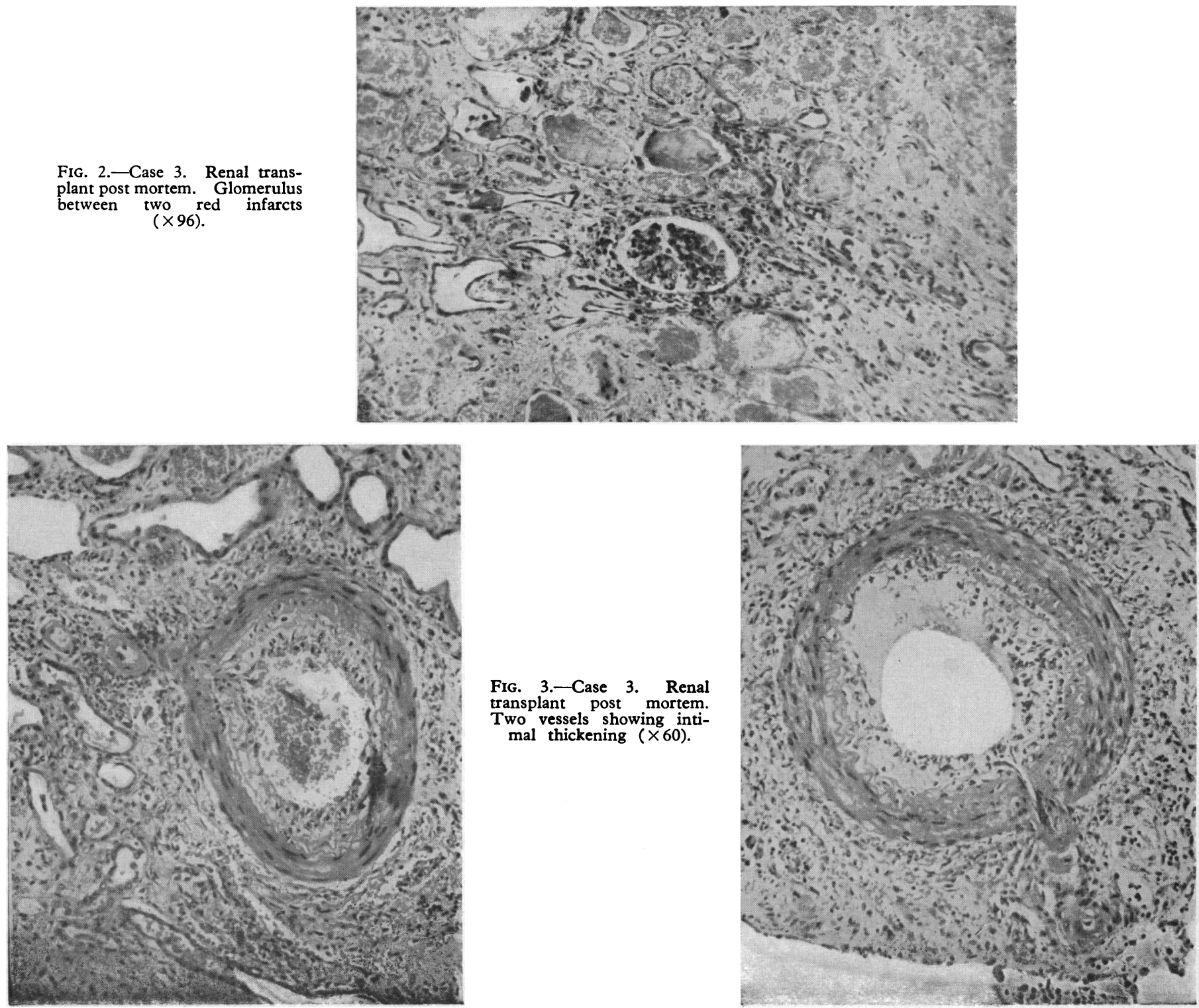

Fig. 3.-Case 3. Renal transplant post mortem. mal thickening $(\times 60)$. 


\title{
Three Clinical Cases of Renal Transplantation
}

\author{
JOHN HOPEWELL,* F.R.C.S. ; ROY YORKE CALNE, † § M.S., F.R.C.S. \\ ISOBEL BESWICK, $¥$ M.D.
}

[With Special Plate]

Brit. med. F., 1964, 1, 411-413

Woodruff et al. (1962) have made a plea that all cases of clinical renal transplantation be published so that the material will be freely available for workers in this field. This is obviously desirable in view of the relatively small numbers of human transplants performed by each group. It is in compliance with these requests that we now publish records of three cases of renal transplantation, two of cadaveric grafts and one from a living donor, the patient's father.

In these cases it was planned to attempt to inhibit the homograft reaction by chemical means only, and mercaptopurine was chosen as the best agent available at the time on experimental grounds.

\section{Case 1}

A married woman aged 50 was admitted to hospital on 29 October 1959 with polycystic disease of the kidneys. Her blood-pressure was $165 / 70$, with left ventricular hypertrophy and early heart failure. Blood urea $340 \mathrm{mg} . / 100 \mathrm{ml}$; Hb $66 \%$; blood group A, rhesuspositive. Urine: pus cells + ; culture: Pseudomonas pyocyanea. On 6 November an attempt was made to carry out a cadaveric graft from a female subject who had succumbed from a subarachnoid haemorrhage resulting from rupture of a congenital aneurysm of the circle of Willis. On exploration of the kidneys for the purpose of effecting transplantation, bilateral polycystic disease was discovered. The association of this condition with congenital aneurysm of the circle of Willis was then recalled.

On 17 November a cadaveric graft was taken from a male donor aged 61 who had suffered from essential hypertension and acute bronchitis (blood urea $36 \mathrm{mg} . / 100 \mathrm{ml}$. ; blood group A, rhesuspositive). It was inserted into the right iliac fossa by the transperitoneal route with anastomosis of the main renal artery to the internal iliac artery and of the renal vein to the common iliac vein. An aberrant vessel to the lower pole of the graft was anastomosed to the inferior epigastric artery. The capsule was not split; the ureter was implanted into the bladder over a polythene tube brought out through the urethra. Dosage of mercaptopurine (body weight $70 \mathrm{~kg}$.): 17 November, $200 \mathrm{mg}$. intramuscularly; 18 November, $125 \mathrm{mg}$. orally; 19 November, $75 \mathrm{mg}$. orally.

In the 48 hours following operation urinary output was very poor and death occurred at $7.30 \mathrm{a} . \mathrm{m}$. on 20 November, when the blood urea was $500 \mathrm{mg} . / 100 \mathrm{ml}$. ; calcium $6.5 / 100 \mathrm{ml}$; ; potassium $4.1 \mathrm{mEq} / \mathrm{l}$. ; chloride $101 \mathrm{mEq} / \mathrm{l}$. ; sodium $147 \mathrm{mEq} / 1$. ; bicarbonate 12 vols. $\mathrm{CO}_{2} \%$.

Post-mortem examination confirmed the presence of bilateral polycystic disease of the patient, with no recognizable glomeruli to be seen. Death was due to bronchopneumonia and uraemia, possibly precipitated by the inhalation of some stomach contents. Histological examination of the transplanted kidney showed some dilatation of the tubules with areas of regeneration following tubular necrosis. Focal scars were seen and the small arteries appeared hyperplastic. The glomerular capillary walls were thickened. There was a small infarct at the lower pole in the area supplied by the aberrant artery.

$\star$ Consultant Surgeon.

t Registrar, Royal Free Hospital, London.

$\ddagger$ Honorary Consultant and Senior Lecturer, Department of Pathology, Royal Free Hospital, London.

$\checkmark$ Now Honorary Consultant and Senior Lecturer, Surgical Unit, Westminster Hospital, London.

\section{Case 2}

A married Jamaican woman aged 22 had chronic pyelonephritis with hypertension and papilloedema. She had had pregnancies in 1952, 1956, and 1957 (abortion), with albuminuria and hypertension in each case. Acute gonococcal infection was successfully treated in 1957.

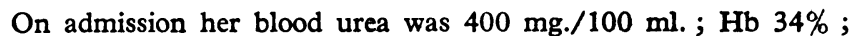
blood group O, rhesus-positive; B.P. 180/120. It was necessary to haemodialyse her on 16 February and 1 March 1960 . Blood urea after dialysis was $123 \mathrm{mg} . / 100 \mathrm{ml}$. and $112 \mathrm{mg} . / 100 \mathrm{ml}$. respectively.

On 4 March renal transplantation was carried out using a cadaveric graft from a female donor aged 72 whose death occurred at operation for acute cholecystitis complicating prolonged steroid therapy for haemolytic anaemia (blood group B, rhesus-positive). The graft was placed in the right iliac fossa by the transperitoneal route with anastomosis of the renal artery to the internal iliac artery and of the renal vein to the common iliac vein, with implantation of the ureter into the bladder. Anoxic period 1 hour 50 minutes. Dosage of mercaptopurine (body weight $50 \mathrm{~kg}$.): 4 March, $125 \mathrm{mg}$. intramuscularly ; 5-9 March, $125 \mathrm{mg}$. orally; $10 \mathrm{March}, 50 \mathrm{mg}$. orally.

After the transplantation the daily urinary output varied from 20 to $60 \mathrm{ml}$. The patient suffered an intestinal ileus with increasing uraemia, the blood urea on 14 March being $365 \mathrm{mg} . / 100 \mathrm{ml}$. Death occurred on 15 March.

Post-mortem examination confirmed the presence of chronic pyelonephritis and the changes of malignant hypertension, with some histological features suggesting an underlying chronic glomerulonephritis (Ellis type I), though the more recent changes in the nephrons made it impossible to be sure of this. The vascular anastomoses of the graft were intact, but there was extensive thrombosis in the iliac artery and the transplanted renal artery and vein which had occluded the vessels of the graft. This was necrotic and had probably been so for several days.

\section{Case 3}

A youth aged 17, with congenital hypoplasia of the kidneys and chronic pyelonephritis, was admitted to hospital in August 1960. His B.P. was $190 / 110$; blood urea $200 \mathrm{mg} . / 100 \mathrm{ml}$; Hb $61 \%$. Urine was sterile. Fundi showed grade 1 hypertensive changes.

$\mathrm{He}$ was referred to a colleague in 1957 on account of pain occurring during and for a few seconds after micturition. Investigations at that time showed a sterile pyuria with no evidence of tuberculosis on culture or guinea-pig inoculation. The excretion urogram at that date showed adequate concentration of the contrast medium. There were congenital anomalies of both kidneys. The right kidney was small and lobulated, with no obvious development of minor calices to the lower pole, and hydronephrosis of the upper and middle calices. There was only a small rim of cortex. The left kidney was a little larger but was also irregular in outline, especially in its lower part, and there was some splaying of the calices consistent with the presence of a medium-sized cyst. The upper ureters on both sides were a little dilated, but the lower portions seemed normal. There was no evidence of obstruction of the bladder neck.

He remained well for the next three years, leading an active life, and able to play football. In July 1960 he was off work with a sore throat, and three weeks later began to notice that his face and legs were swollen. He was admitted to hospital, still with 
swelling of the face and legs. Despite treatment, his anaemia and uraemia were progressing. On 5 September his $\mathrm{Hb}$ was $48 \%$. Its correction by transfusion was undertaken and constant watch was required to prevent the onset of congestive cardiac failure.

On 26 September a corrected creatinine clearance rate was 3.9 $\mathrm{ml} . / \mathrm{min} . / 1.73 \mathrm{sq} . \mathrm{m}$., the glomerular filtration rate, estimated as creatinine clearance, being $3.1 \%$ of normal. The B.P. had risen to $240 / 140$ and the blood urea to $350 \mathrm{mg} . / 100 \mathrm{ml}$.

His father was investigated, having volunteered to donate a kidney. The patient was his youngest son, his other children being self-supporting. He was aged 54, fit, and active. His urine was clear and sterile and the blood urea was normal. On intravenous pyelography the function of both kidneys was quite normal, but in the upper pole of the left kidney there was a small calculus. Comparison of blood groups between him and his son were:

\begin{tabular}{|c|c|c|c|c|c|c|c|c|c|c|c|}
\hline & $\mathrm{ABO}$ & $\begin{array}{c}\mathrm{Rh} \\
\text { Pheno- } \\
\text { type }\end{array}$ & $\begin{array}{l}\text { Probable } \\
\text { Genotype }\end{array}$ & $M N$ & $S$ & $P_{1}$ & Lua & $\mathbf{K}$ & $\mathrm{Le}^{\mathrm{q}}$ & Leb & Fya \\
\hline $\begin{array}{l}\text { Patient } \\
\text { Father }\end{array}$ & $\begin{array}{l}O \\
O\end{array}$ & $\begin{array}{l}\text { CcDee } \\
\text { CCDee* }\end{array}$ & $\begin{array}{l}\text { CDe/cde } \\
\mathrm{CDe} / \mathrm{CDe}\end{array}$ & $\begin{array}{l}M N \\
M N\end{array}$ & \pm & $\begin{array}{l}+++ \\
+++\end{array}$ & $=$ & $\bar{z}$ & \pm & $\bar{t}$ & + \\
\hline
\end{tabular}

- There was evidence of mixed-cell population with the anti-c serum, so that it was difficult to decide the exact genotype, but $R_{1} R_{1}$ seemed more likely
than $R_{1}$.

The leucocytes of the donor were cross-matched against the patient's, using saline and antiglobulin consumption techniques, and no incompatibility was detected. The red cells of the donor were also cross-matched against his son's serum, using saline and albumin techniques at $4^{\circ} \mathrm{C}$, , room temperature $37^{\circ} \mathrm{C}$, , as well as common iliac vein of the patient, using a right iliac muscle-cutting incision and an extraperitoneal approach. The ureter was anastomosed to the bladder without an indwelling catheter. ${ }^{2}$

The dosage of mercaptopurine was as follows (see also Chart): 30 October, $2 \mathrm{mg} . / \mathrm{kg}$. orally ; 31 October to 2 November, $2 \mathrm{mg} . / \mathrm{kg}$. intramuscularly ; 3-11 November, 1-2.5 mg./kg. daily ; 17 and 18 , $4 \mathrm{mg} . / \mathrm{kg}$. daily ; 19 , nil ; 20 and $21,2 \mathrm{mg} . / \mathrm{kg}$. daily ; 22 and 23 , $4 \mathrm{mg} . / \mathrm{kg}$. daily; $24,2 \mathrm{mg} . / \mathrm{kg}$. daily; $25,3 \mathrm{mg} . / \mathrm{kg}$. daily; 26 , $5 \mathrm{mg} . / \mathrm{kg}$. daily; $29,2 \mathrm{mg} . / \mathrm{kg}$. daily.

After operation the patient's general condition improved immediately, his nausea and distress being relieved on recovery from the anaesthetic. There was a fall in the raised serum potassium on the day after operation. Blood urea rose slowly to $470 \mathrm{mg}$. on the fourth post-operative day, when there was a marked increase in urinary output, to the neighbourhood of 3 litres/day. Accompanying this diuresis was a steady fall in the blood urea to a low level of $160 \mathrm{mg}$. on the 16 th and 17 th post-operative days.

On the 10th day after operation the patient began to run a temperature of $100^{\circ} \mathrm{F}$. $\left(37.8^{\circ} \mathrm{C}\right.$.) at night, and two days later complained of some malaise. Mercaptopurine was discontinued at that time, and deterioration continued with a fever of up to $105^{\circ} \mathrm{F}$. $\left(40.6^{\circ}\right.$ C.) and gradual diminution in urinary output from 5.1 to 2.51 . in the 24 hours. There was no evidence of infection, and the condition was taken to be a toxic homograft reaction. Renal biopsy on 17 November (Special Plate, Fig. 1) tended to confirm this conclusion, showing considerable oedema and cellular infiltration, mononuclear and polymorphonuclear. The tubular cell nuclei appeared normal in shape and well stained, with some areas of necrosis and regeneration. Bi-refringent crystals were seen. An increased dosage of mercaptopurine was resumed. The patient's
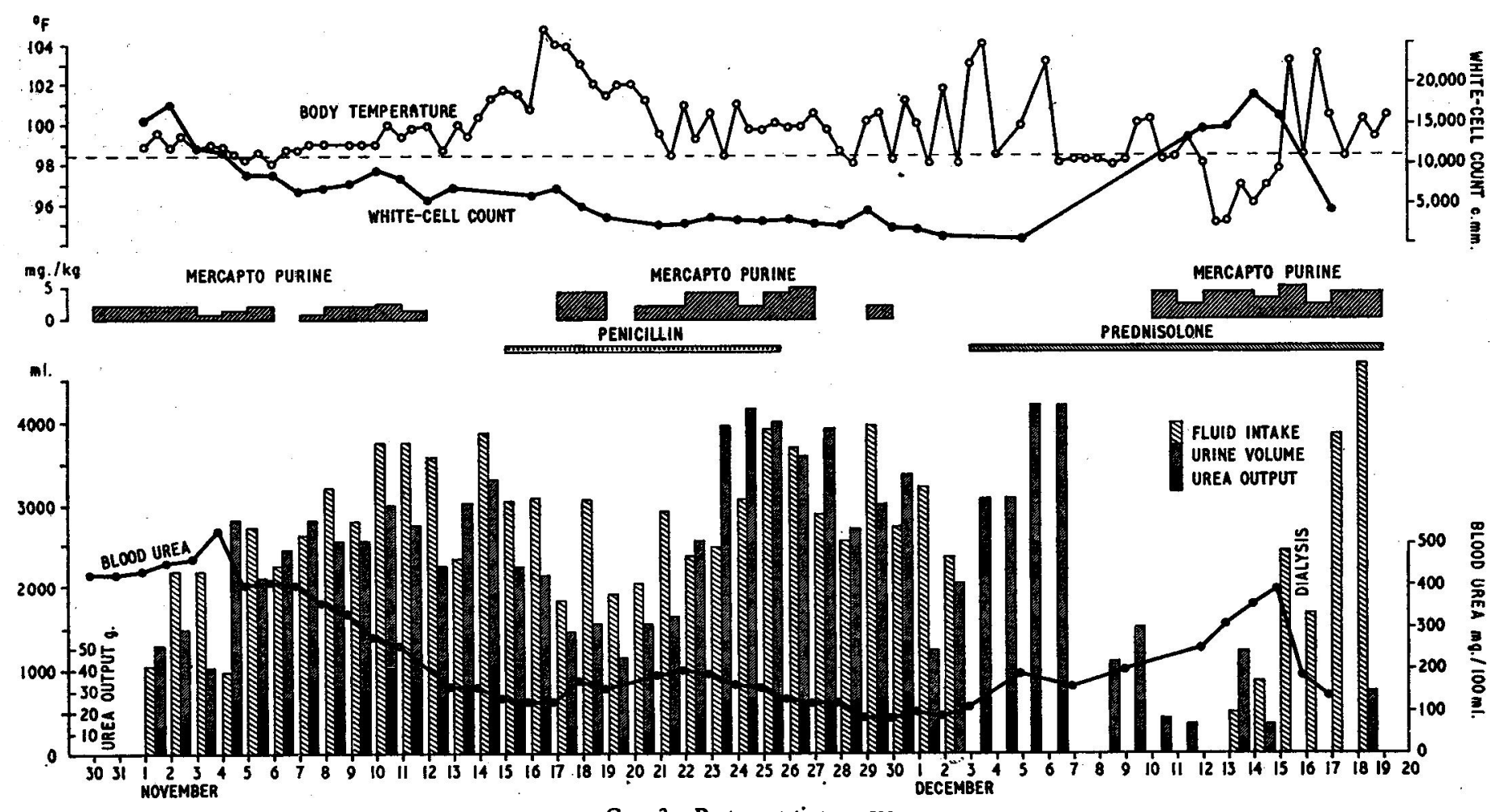

Case 3. Post-operative course.

by LO modified WS enzyme and indirect antiglobulin techniques at $37^{\circ} \mathrm{C}$. At the same time the patient's serum was screened against a panel of cells of known genotypes for possible red-cell antibodies. No abnormality was detected. (For these investigations we are indebted to Dr. Kenneth Goldsmith, of the Hood Group Reference Laboratory at the Lister Institute, Chelsea Bridge Road, London S.W.1.)

The patient was prepared by haemodialysis on 19 October. The blood urea was thereby reduced to $105 \mathrm{mg} . / 100 \mathrm{ml}$. The operation for transplantation was, however, delayed for 11 days, by which time the blood urea had risen to $430 \mathrm{mg}$.

Transplantation of the donor's left kidney was carried out on 1 November under hypothermia with anastomosis of the renal artery to the internal iliac artery and of the renal vein to the general condition improved. There was slow resolution of the fever and urinary output increased again. In the fourth week there was a steady output of urine of $41 . /$ day, and the blood urea fell to $85 \mathrm{mg} . / 100 \mathrm{ml}$. on 20 November. The white-cell count, however, was steadily falling and it was judged necessary again to discontinue mercaptopurine. Thereafter urinary output again fell and there was a slow rise of blood urea. This deterioration was in no way controlled by prednisolone in doses of $25-65 \mathrm{mg}$./day. At the end of the fifth week the patient complained that the graft was painful ; it became tender and swollen, appearing as a readily palpable and tender mass in the right iliac fossa. Mercaptopurine was again

${ }^{1}$ My assistants at this operation were Mr. Lionel Gracey, senior registrar, R.F.H., and Mr. Wallace Eady, now consultant surgeon, Grimsby Hospital.-J. H. 
resumed (2-4 mg. $/ \mathrm{kg}$ ) and within 48 hours the signs and symptoms relating to the graft had regressed, but on this occasion there was no accompanying improvement in renal function. The blood urea rose to $400 \mathrm{mg}$ at the end of the sixth week after operation and haemodialysis was again carried out. Urinary output remained low ; the patient died on the 49 th post-operative day.

At post-mortem examination the patient's own kidneys showed chronic pyelonephritis with very severe scarring and reduction of renal tissue ; this was probably superimposed upon congenital hypoplasia. The grafted kidney was enlarged to about two and a half times normal size. The vascular anastomoses were sound and free from thrombosis. On microscopical examination there were several striking features. Numerous areas of recent haemorrhagic necrosis were present in the cortex; these rather resembled infarcts, but vascular thrombosis was not seen (Special Plate, Fig. 2). Many nephrons showed evidence of ante-mortem necrosis, including regeneration of tubular epithelium. Moderate numbers of glomeruli survived and appeared normal, though a few showed fibrinoid transformation of occasional capillary loops. Medium-sized and small arteries in the substance of the kidney showed intimal thickening (Special Plate, Fig. 3).

An unexpected finding was the presence of patches of caseating tuberculosis in the grafted kidney, containing many tubercle bacilli. Miliary tubercles were scattered in other organs and tissues of the body. The donor has survived in good health with no evidence of tuberculous infection.

It was not determined how the tuberculous infection was acquired. The patient was nursed in an isolation unit by staff fully trained in isolation methods and there was no evidence in the wound or elsewhere of infection by pyogenic organisms.

\section{Discussion}

The first two cases, those of cadaveric grafts, are presented for the record, the first case emphasizing the problem of selecting a suitable cadaveric graft. In the third case there was a classical picture of a homograft reaction which resolved, coincidentally at least, with the administration of mercaptopurine in doses of approximately $4 \mathrm{mg} . / \mathrm{kg}$. body weight. After the withdrawal of mercaptopurine there was further deterioration in renal function, and finally the extreme picture of an enlarged painful and tender graft was presented. On resumption of mercaptopurine at this stage again these signs and symptoms were reversed, but on this occasion without restoration of adequate function. The miliary tuberculous infection points the need for vigilance in the care of patients whose natural defences are reduced. Those likely to result from outside infection are well recognized and precautions are taken against them, but it seems at least that present infection to which an adequate immunity has been developed in the healthy state may flare up with the administration of an agent known to reduce protective mechanisms.

An attempt has been made recently to review the whole picture of clinical renal transplants (Calne, 1963). The urgent need for kidney transplantation is a source of concern to clinicians and of distress to patients and their relatives, especially in view of the immense publicity that some attempts at clinical transplantation have received.

In view of the lack of knowledge of basic data, most of the clinical work has been undertaken empirically. The results have on the whole been disappointing, although a few notable successes have been achieved. Thus two patients with kidneys from unrelated donors have survived more than six months and three patients with kidneys from relatives have survived for more than one year. This limited success would encourage workers to persevere with clinical transplantation, even though routine clinical use of kidney grafts is by no means justified. With no treatment of the recipient at all, a kidney from an unrelated donor has functioned for as long as five and a half months in a recipient with chronic uraemia (Hume et al., 1955). At the other extreme typical rejection has occurred as early as three weeks. At the presen time, therefore, it is quite impossible to know how important are the factors of genetic relationship, chronic uraemia, and irradiation or chemotherapy in each isolated transplant that is performed. There is not the slightest doubt that sublethal irradiation does not significantly prolong the functional survival of canine renal homografts, but the thiopurine drugs have been shown by independent groups of workers to have a definite effect in inhibiting the rejection process in dogs. Although these drugs produce variable and unpredictable results, sometimes remarkable success has been achieved (Pierce and Varco, 1962).

It is to be hoped that future clinical programmes will be designed so as to obtain a maximum of research data. In view of the considerable requirements of manpower and equipment to perform a clinical transplantation, the number of patients that can be handled is limited. For progress to occur as swiftly as possible it would seem to be essential that individual groups co-operate with each other so that mistakes are not repeated and advances can be rapidly developed. It is in the hope that full records will allow a more coherent picture to emerge that these cases are published.

\section{Summary}

Three clinical cases of renal homotransplantation are presented, in two of which the graft was taken from a cadaver and in the third from a living donor. They are published to comply with the expressed wish of workers in this field for a record of all attempted clinical cases of whole-organ grafting. Details are given of the patients' age, diagnosis, clinical condition, and laboratory reports, including records of the blood group of recipient and donor. The site and technique of grafting are recorded. In each case mercaptopurine was used in the attempt to modify the homograft reaction, and details of dosage are given.

The two patients receiving cadaveric kidneys died in the first few days after operation, while the one receiving a "live" kidney graft survived for seven weeks. An account of this patient's course and management during that period is given.

Evidence is afforded of the development of a homograft reaction and of some temporary control by mercaptopurine. Death occurred as a result of renal failure, but post-mortem examination demonstrated also a widespread miliary tuberculosis, and the implications of these findings are discussed.

\section{REFERENCES}

Calne, R. Y. (1963). Renal Transplantation. Arnold, London. Hume, D. M., Merrill, J. P., Miller, B. F., and Thorn, G. W. (1955). f. clin. Invest., 34, 327.

Pierce, J. C., and Varco, R. L. (1962), Lancet, 1, 781

Woodruff, M. F. A., Robson, J. S., McWhirter, R., Nolan, B., Wilson T. I., Lambie, A. T., MciWilliam, J. M., and MacDonald, M. K.
(1962). Brit. f. Urol., 34, 3. 